NORDISK MUSEOLOGI $1993 \cdot 2$, s. 3-5

\title{
The Genealogy of THE MUSEUM
}

\author{
Annesofie Becker
}

The title of the symposion was "The Genealogy of the Museum". Why did we use a word from ancient Greek? Why not just call it "The History of the Museum" or "The pedigree of the Museum"? Why did we give priority to the museum's temporality? In the course of the last ten years, the museum world has been subjected to a great deal of change. We only know that there has certainly beeen a museum's boom and that, quoting Walter Grasskamp, "the museum has become the metaphor for our time". Just a few years ago, the question was whether or not there would still be a museum in the future. But this is no longer the case. No, the question now is whether or not there will be a future for the museum. Today, the anxiety about the future itself is greater and more real than any anxiety about the future of the museum.

The development has occurred at such a rapid pace that it is difficult to imagine what the museum of the future will be. In such a predicament, it is only human to turn our gaze backwards and to take refuge in history in the hope of finding some answers there. We might also formulate the current situation in this way - the crisis of the museum's very existence has been replaced by a crisis of orientation, a crisis of meaning.

That is the way it often happens in the affluent surplus society. There is no shortage of museums, but we are short of knowing what we want with the museum. That is why we put the temporality of the museum on the agenda for the symposion. Where will the development lead to? This is certainly one of the questions, albeit in parenthesis, which we have wanted to raise with the exhibition, Museum Europa.

But then, why did we not just entitle the symposion "The History of the Museum"? Why did we replace 'history' with 'genealogy'? We used the word 'genealogy' because we do not take it for granted that history has a continuous linear development. We want to dissociate ourselves from traditional linear historiography. We would prefer to avoid forward and backward projection. We are most reluctant, in any event, to impose present-day categories upon the past. After all, it has been a long time since anybody dared to assert that we are living in the best of all possible worlds. 


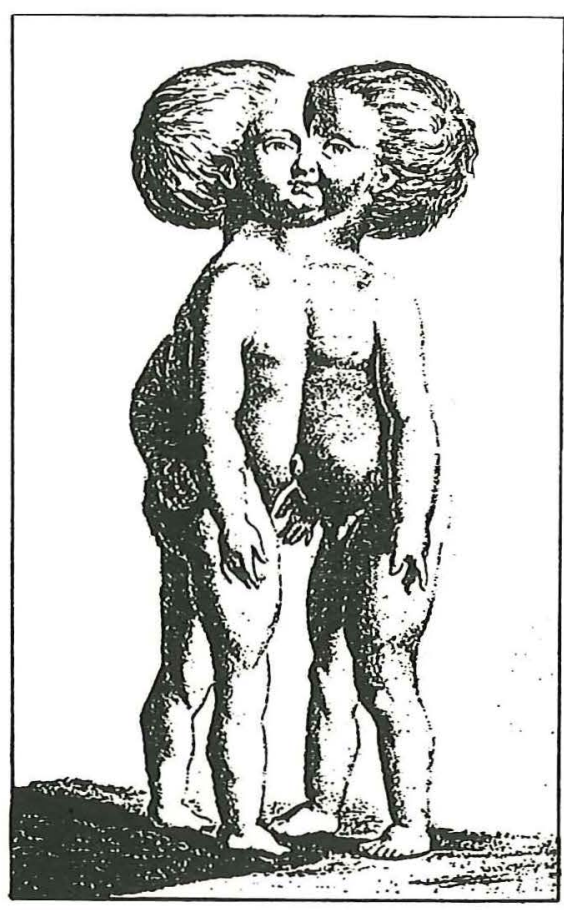

Illustration from the Museum Europa exhibition catalogue

In traditional historical scholarship, the questions about the museum's history, about the museum's origin, have been based on the assumption that there is some particular God-given, inherently inevitable, immutable prototype of museum, that has only beeen dressed up in the various robes of the times. With this assumption in mind, the concern of the museum historian has been to focus his or her X-ray vision in order to look through the historical disguise and penetrate to the core of the matter, to attain the essence, that which is the museum's true self. Paradoxically enough, the traditional museum historian has in fact presupposed a museum-essence that is removed from history, an essence which the various museums through time should have brought into manifestation, in different degrees.

With the concept of 'genealogy' we wanted to accentuate a distance, or even more - we wanted to liberate ourselves from the traditional means and methods of museum's historical inquiry and museology. In such a way the word was introduced by Nietzsche with his book "Zur Genealogie der Moral" (1887) and again today by more contemporary Nietzscheans like Michel Foucault. Whereas history would indicate that which is indispensable, and therefore unavoidable, in the museums of our time, genealogy promises to unveil that which is accidental, and therefore variable, about the present condition of things. Whereas traditional historical investigation fixates the past as a preliminary stadium of the present, 'genealogy' construes the past as an image that is in contrast with the present. And this allows us to think about the future in an entirely different way.

The genealogical viewpoint does not make any claim that it is imperative to discover the one and only true museum. Instead the museum genealogist goes ahead in much the same manner as Peer Gynt, the character from Henrik Ibsen's play. $\mathrm{He}$ or she peels the museum as if it were an onion. Unlike Peer Gynt, how-ever, he or she does not throw the onion skins away, only to despair about the empty essence. No, to the museum genealogist, the museum is precisely the accidental sum and sequence of onion skins. The museum vanishes upwards into the conditions of its progress and its lineage; it is nothing more and nothing less than its own historical conditions of possibility 


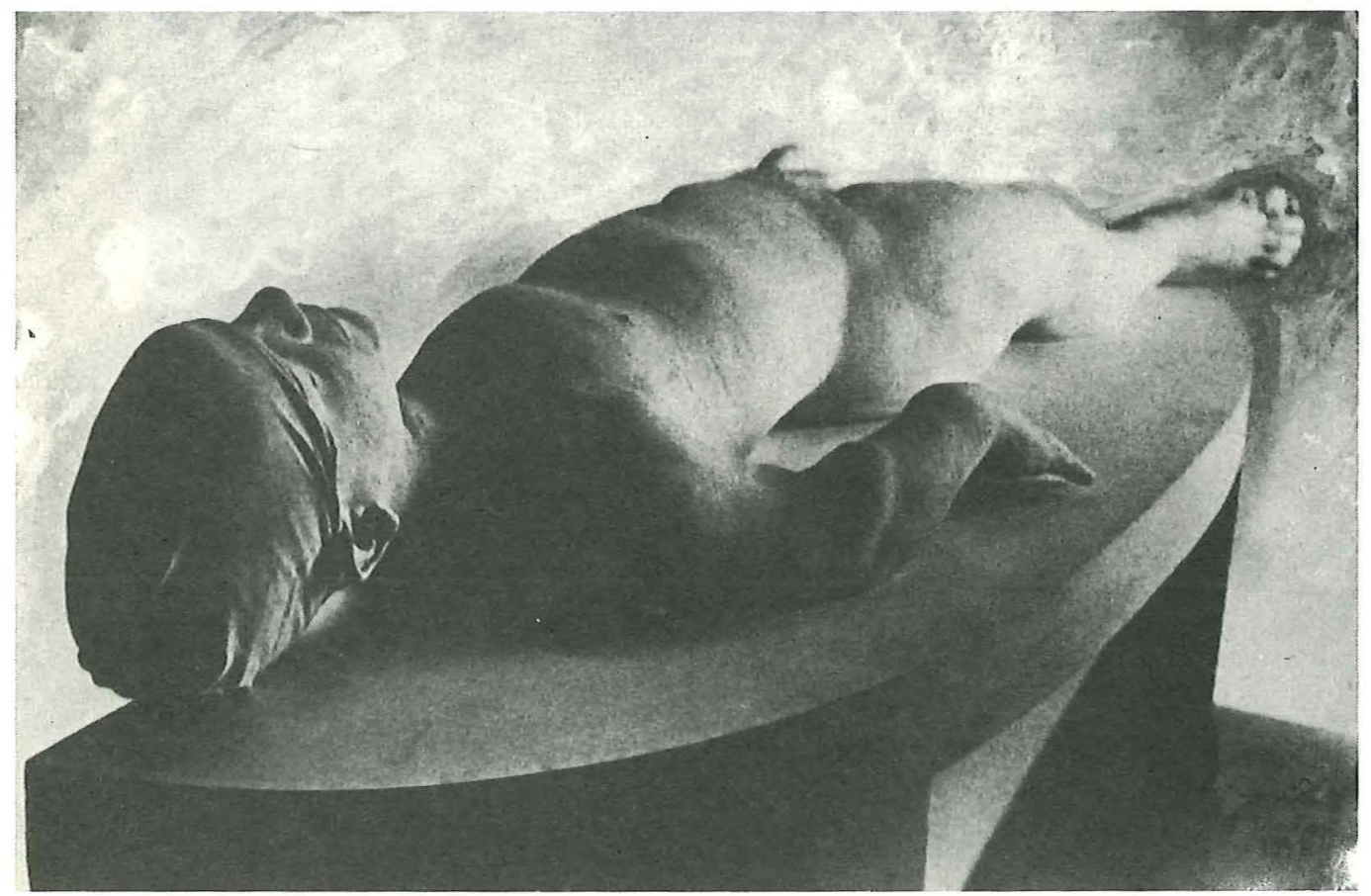

From the exhibition Museum Europa. Source: The exhibition catalogue.

and progress. And therefore, the genealogist takes history more seriously into account than the traditional historian; each and every layer of the onion's skins becomes interesting.

Every epoch contrives its own museums. The museums that we have today are not ripened versions of museums that were somehow previously more naive. No, they are distinctive cultural institutions that are specific for our time. They are the result of a complex interplay of a multitude of accidental historical facts. We can venture to mention a random sampling of these: the tourist trade; the modern alliance betweeen economics, politics and culture; the electronic media; the preservation of culture as a compensation for the loss of nature; the modern culture of experience and event; the professionalization and mechanization of cultural administration, and so on.

As everybody knows, the eyes begin to sting when you are peeling an onion. But it was my hope, nevertheless, that during the course of the symposion, many onions would be peeled. Onions are rich in nutrition, they taste good, and they can be prepared in many, many ways.

Annesofie Becker är utställningsproducent och har lett arbetet med 'Museum Europa' sedan projektet inleddes 1989.

Adr: Danmarks Nationalmuseum, Frederiksholms Kanal 12, DK-1220 Köbenhaun K. FAX +45133148411. 